\title{
Biochemical and photosystem characteristics of wild-type and Chl b-deficient mutant in tree peony (Paeonia suffruticosa)
}

\author{
L.X. ZHANG ${ }^{*, \dagger}$, Q.S. CHANG ${ }^{* *,+,}$, X.G. HOU ${ }^{*,+}$, S.D. CHEN", Q.M. ZHANG ${ }^{* *}$, J.Z. WANG ${ }^{* * *}$, \\ S.D. LIU", and S. LI* \\ College of Agriculture, Henan University of Science and Technology, 471000 Luoyang, China* \\ College of Horticulture and Plant Protection, Henan University of Science and Technology, 471000 Luoyang, \\ China* \\ Luoyang Greening Management Center, 471000 Luoyang, China ${ }^{* * *}$ \\ Luoyang International Peony Garden, 471000 Luoyang, China
}

\begin{abstract}
In order to explore the adaptive strategies of tree peony $y l 1$ mutant in response to photooxidative stress, the changes of biochemical parameters, chlorophyll fluorescence, and the modulated $820-\mathrm{nm}$ reflection of $y l 1$ mutant and wildtype plants were compared. We found the activities of superoxide dismutase and catalase, the contents of soluble protein, proline, superoxide radicals, hydrogen peroxide, malondialdehyde, and relative electrical conductivity were significantly higher than those of the wild type. The photochemical efficiency of PSII significantly decreased, while the proportion of heat dissipation of $y l l$ mutant increased greatly. The donor and acceptor side and electron transfer of PSII were greatly inhibited. Meanwhile, the performance of PSI and coordination of two photosystems decreased markedly in $y l l$ mutant. The $y l l$ mutant could reduce the damage caused by photooxidative stress by increasing the activity of antioxidant enzymes, the content of some osmoregulatory substances, and the proportion of heat dissipation.
\end{abstract}

Keywords: antioxidants; chlorophyll fluorescence; modulated 820-nm reflection; photosynthetic capacity; $y l 1$ mutant.

\section{Introduction}

Leaves are the main organs of photosynthesis in higher plants, and chlorophyll (Chl) in leaves plays an important role in absorbing and converting light energy, so the biosynthesis and degradation of Chl are very important for photosynthesis of plants (Wang et al. 2018). The decrease of Chl content often leads to the decrease of photosynthetic capacity, poor growth, and development, and even the decrease of biomass (Liu et al. 2016a, Lai et al. 2018). Therefore, Chl-deficient mutants are ideal materials for studying the mechanism of photosynthesis, the structure and function of the photosystems, and Chl biosynthesis, and are valuable for cultivating excellent varieties and molecular marker-assisted breeding (Zhang et al. 2020). Leaf-color mutants with yellow leaves, variegated leaves, stripes, and other characteristics have a high ornamental value in landscaping. Among them, a yellow-leaf mutant is a common mutation type. The paulownia (Paulownia fortnnei) mutant with white flowers presented light green leaves at the seedling stage, they turned yellow at the mature stage, and had a certain ornamental value (Ru et al.

\section{Highlights}

- Higher photooxidative damage was reported in tree peony yll mutant compared to the wild type.

- The function and coordination of two photosystems in $y l 1$ mutant decreased significantly.

- The yll mutant increased the contents of antioxidants and osmoregulants and heat dissipation capacity in response to photooxidative stress.
Received 2 December 2020

Accepted 15 March 2021

Published online 12 April 2021

${ }^{+}$Corresponding authors

e-mail: : hkdcqs@126.com (Q.S. Chang) hkdhxg@haust.edu.cn (X.G. Hou)

Conflict of interest: The authors declare that they have no conflict of interest.

These authors contributed equally to this work. 
2017). The young leaves of yellow-leaf mutant 'Golden Qilu' changed from orange yellow to golden yellow in spring, and then gradually turned green, which greatly improved the ornamental value of Acer truncatum (Chu 2020).

Carotenoids (Car) play an important role in protecting photosynthetic apparatus from photooxidative damage by reactive oxygen species(ROS), and some leaf-color mutants are vulnerable to oxidative stress due to concomitant lack of Car (Chai et al. 2011, Kalaji et al. 2017). The contents of malondialdehyde (MDA), hydrogen peroxide, and superoxide radical $\left(\mathrm{O}_{2}{ }^{--}\right)$in the leaves usually increase, resulting in damage to leaves (Guo 2020). Many leaf-color mutants can reduce the damage caused by ROS, prevent the aggravation of membrane lipid peroxidation, and improve resistance by increasing the contents of osmotic substances and the activities of antioxidant enzymes ( $\mathrm{LV}$ 2010, Li 2016). Although the content of MDA increased in the paulownia ( $P$. fortunei) yellowing mutant ( $\mathrm{Ru}$ et al. 2017) and the thin-skinned melon (Cucumis melo) natural yellowing to green mutant (Lai et al. 2018), the activities of superoxide dismutase (SOD), peroxidase (POD), and catalase (CAT) were markedly enhanced to reduce the damage caused by membrane lipid peroxidation.

Photosynthesis involves the absorption, transfer, and transformation of light energy, which depends on the coordination of PSII and PSI; the capture and distribution of light energy are the core of photosynthesis (Du et al. 2019). As a noninvasive and highly sensitive method, Chl fluorescence technique can accurately evaluate the function and structure of photosynthetic apparatus, and its measurement parameters are closely related to the function of PSII (Dąbrowski et al. 2015, 2017). Modulated Chl $a$ fluorescence parameters are related to plant carbon assimilation, which mainly reflect the actual light energy utilization and distribution of PSII (Qiu et al. 2013). Prompt Chl fluorescence (OJIP curve) can reflect energy and electron transfer process in thylakoid membranes, the activities of PSII donor and acceptor sides, and the redox changes of the electron transporter (Li et al. 2005, Kalaji et al. 2017). In addition, the modulated 820-nm reflection can be used to assess the functional state of PSI and analyze its coordination with PSII (Zhang et al. 2011, 2017). In Brassica oleracea, minimal fluorescence yield of the dark-adapted state $\left(\mathrm{F}_{0}\right)$, maximal fluorescence yield of the dark-adapted state $\left(\mathrm{F}_{\mathrm{m}}\right)$, minimal fluorescence yield of the light-adapted state $\left(\mathrm{F}_{0}{ }^{\prime}\right)$, maximal quantum yield of PSII photochemistry $\left(\mathrm{F}_{\mathrm{v}} / \mathrm{F}_{\mathrm{m}}\right)$, the efficiency of excitation capture of open PSII center $\left(\mathrm{F}_{\mathrm{v}}{ }^{\prime} / \mathrm{F}_{\mathrm{m}}{ }^{\prime}\right)$, effective quantum yield of PSII photochemistry $\left(\Phi_{\mathrm{PSII}}\right)$, photochemical quenching coefficient $\left(\mathrm{q}_{\mathrm{P}}\right)$, nonphotochemical quenching coefficient $\left(\mathrm{q}_{\mathrm{N}}\right)$, and electron transfer rate (ETR) in yellow-leaf cabbage (Brassica oleracea) mutant 'YL-1' were significantly lower than those of wild type (WT) plant (Yang et al. 2014). In Pseudosasa japonica, the electron transport chain from PSI to PSII was damaged, and the weakening of PSII activity resulted in immature chloroplast development, which might be the direct cause of the difference in leaf color of this species (Chen et al. 2018).

At present, there are few studies on leaf-color mutants combining two techniques (modulated fluorescence and prompt Chl fluorescence), and there is a lack of research on the PSI activity of leaf-color mutants. Our previous work showed that the natural yellowing mutant ' $y l l$ ' of Paeonia suffruticosa Andr. cv. 'Wu Long Peng Sheng' is a 'chlorina' mutant with the low content of total $\mathrm{Chl}$ and $\mathrm{Chl} b$, abnormal thylakoid structure, and reduced photosynthetic capacity (Chang et al. 2019). However, few studies have comprehensively focused on the functions of two photosystems in $y l l$ mutant of tree peony. The $y l l$ mutant could tolerate photooxidation damage in April, so we hypothesized that it had a corresponding adaptive strategy to photodamage. In this study, the physiological changes,

Abbreviations: $\mathrm{ABS} / \mathrm{CS}_{0}$ - absorption flux per $\mathrm{CS}$ (at $\mathrm{t}=0$ ); $\mathrm{ABS} / \mathrm{RC}$ - absorption flux per reaction center $(\mathrm{RC})$; CAT - catalase; $\mathrm{D}$ - the fraction of light energy utilized in thermal dissipation; $\mathrm{DI}_{0} / \mathrm{CS}_{0}-$ dissipated energy flux per $\mathrm{CS}($ at $\mathrm{t}=0) ; \mathrm{DI} / \mathrm{RC}^{-} \mathrm{dissipated}$ energy flux per RC (at $\mathrm{t}=0)$; $\mathrm{E}$ - the fraction of absorbed energy that is in excess of that which can be thermally dissipated or used in photochemistry; $\mathrm{ET}_{0} / \mathrm{CS}_{0}$ - electron transport flux per CS (at $\left.\mathrm{t}=0\right) ; \mathrm{ET}_{0} / \mathrm{RC}$ - electron transport flux per $\mathrm{RC}($ at $\mathrm{t}=0)$; ETR - electron transfer rate; $\mathrm{F}_{0}-$ minimal fluorescence yield of the dark-adapted state; $\mathrm{F}_{0}{ }^{\prime}$ - minimal fluorescence yield of the light-adapted state; $F_{m}$ - maximal fluorescence yield of the dark-adapted state; $F_{m}{ }^{\prime}-$ maximal fluorescence yield of the light-adapted state; $F_{v} / F_{m}-$ maximal quantum yield of PSII photochemistry; $\mathrm{F}_{\mathrm{v}}{ }^{\prime} / \mathrm{F}_{\mathrm{m}}{ }^{\prime}$ - the efficiency of excitation capture of open PSII center; $\mathrm{I}_{0}$ - the average of the 820-nm transmission signal between 0.4 and $10 \mathrm{~ms} ; \mathrm{I}_{\mathrm{m}}$ - the average of the $820-\mathrm{nm}$ transmission signal between 3 and $10 \mathrm{~s} ; \mathrm{M}_{0}$ - the initial slope of the relative variable fluorescence of the relative rate at which $\mathrm{Q}_{\mathrm{A}}$ is reduced; MDA - malondialdehyde; MR - the light reflectance value of $820 \mathrm{~nm}$ during the illumination process; $\mathrm{MR}_{0}$ - the light reflectance value of the initial illumination (taken from $0.7 \mathrm{~ms}$ in this study, the first credible MR measurement value); MR/MR - the 820 -nm modulated reflection; OEC - oxygen-evolving complex; OJIP - transient Chl $a$ fluorescence rise induced during a dark-to-strong light transition; $\mathrm{P}$ - the fraction of absorbed light energy used for PSII photochemistry; $\mathrm{PI}_{\mathrm{ABS}}$ - performance index on absorption basis; POD - peroxidase; Pro - proline; $\mathrm{q}_{\mathrm{N}}$ - nonphotochemical quenching coefficient; $\mathrm{q}_{\mathrm{P}}$ - photochemical quenching coefficient; $\mathrm{RC} / \mathrm{CS}_{0}$ - density of RCs per excited cross-section $(\mathrm{CS})($ at $\mathrm{t}=0$ ); $\mathrm{REC}-$ relative electrical conductivity; ROS - reactive oxygen species; $\mathrm{S}_{\mathrm{m}}$ - normalized total complementary area above the OJIP transient; SOD superoxide dismutase; $\mathrm{SP}$ - soluble protein; $\mathrm{SS}$ - soluble sugar; $\mathrm{TR}_{0} / \mathrm{CS}_{0}-$ trapped energy flux per CS (at $\mathrm{t}=0$ ); $\mathrm{TR} 0 / \mathrm{RC}-$ trapped energy flux per RC (at $\mathrm{t}=0) ; \mathrm{V}_{\mathrm{I}}$ - relative variable fluorescence intensity at the I-step; $\mathrm{V}_{\mathrm{J}}$ - relative variable fluorescence intensity at the J-step; $\mathrm{W}_{\mathrm{K}}$ - the normalized relative variable fluorescence; $\triangle \mathrm{I} / \mathrm{I}_{0}$ - the maximum redox activity of PSI; $\varphi \mathrm{E}_{0}-$ quantum yield for electron transport (at t $=0$ ); $\Phi_{\text {PSII }}$ - effective quantum yield of PSII photochemistry; $\Phi_{(\text {PSIPSII) }}$ - the coordination between PSI and PSII; $\Psi_{0}$ - probability that a trapped exciton moves an electron into the electron transport chain beyond $\mathrm{Q}_{\mathrm{A}}^{-}($at $\mathrm{t}=0)$.

Acknowledgments: This research has been supported by the Natural Science Foundation of Henan Province (182300410082), National Natural Science Foundation of China (U1804233, 31870093, 31800096), Key Technologies Research and Development Program of Henan Province (162102110095, 182102110401, 212102110475), Key Project of Higher Education of Henan Province (16A220005), Student research training program (SRTP) project of Henan University of Science and Technology (2020346). 
modulated Chl $a$ fluorescence, prompt Chl fluorescence, and the modulated $820-\mathrm{nm}$ reflection of $y l 1$ mutant and WT plants were compared in order to improve the further understanding of the theory of leaf color regulation of tree peony, and to provide a theoretical basis for the cultivation of leaf-viewed tree peony cultivars in the future.

\section{Materials and methods}

Plant materials: The $y l l$ mutant and WT plants of $P$. suffruticosa Andr. cv. 'Wu Long Peng Sheng' were planted in the farm of Henan University of Science and Technology $\left(34^{\circ} 33^{\prime} \mathrm{N}, 112^{\circ} 16^{\prime} \mathrm{E}\right)$. The soil in the experimental site is mainly cinnamon soil, with an average annual rainfall of $595 \mathrm{~mm}$, an altitude of about $250 \mathrm{~m}$, and an average annual temperature of $14.1^{\circ} \mathrm{C}$ (Chen and Yuan 2018). The water and fertilizer were managed under normal natural conditions in the open air. Tree peony was about 14 years old; six healthy $y l l$ mutant and wild-type plants were used for experimental analysis in April 2019, respectively. On the basis of visual observation, the leaves of yll mutants were fully extended and kept yellow in April. However, the yellow leaves of $y l l$ mutants were susceptible to photooxidation stress under strong natural light, and even appeared photobleaching in May. Therefore, the leaves in April were used for analysis.

Antioxidant enzymes activities and soluble protein: The leaves $(0.25 \mathrm{~g})$ from the top of tree peony were ground in ice bath with $0.05 \mathrm{M}$ phosphate acid buffer $(\mathrm{pH}$ 7.8) and centrifuged for $15 \mathrm{~min}$ at the speed of 3,000 rpm at $4^{\circ} \mathrm{C}$, then the extract was stored in the refrigerator for the determination. The superoxide dismutase (SOD, EC 1.15.1.1) activity was assayed by the photochemical NBT method according to Li et al. (2018). SOD activity was measured in $3 \mathrm{ml}$ of a reaction mixture containing $50 \mathrm{mM}$ phosphate buffer ( $\mathrm{pH} 7.8$ ), $130 \mathrm{mM}$ L-methionine, $100 \mathrm{mM}$ EDTA, $750 \mu \mathrm{M}$ NBT, $20 \mu \mathrm{M}$ riboflavin, and $200 \mu \mathrm{l}$ of the extract. The reaction was started with $20 \mu \mathrm{M}$ riboflavin by exposing the cuvette to the fluorescent lamp group of $80 \mu \mathrm{mol}$ (photon) $\mathrm{m}^{-2} \mathrm{~s}^{-1}$ for $20 \mathrm{~min}$. The reduction of NBT was determined at $560 \mathrm{~nm}(722 \mathrm{~S}$, Lengguang, Shanghai, China). One unit of SOD activity was defined to inhibit the photoreduction of NBT by $50 \%$. The activity of catalase (CAT, EC 1.11.1.6) was assayed in a reaction mixture of $200 \mathrm{mM}$ phosphate buffer (pH 7.8), $100 \mathrm{mM}$ $\mathrm{H}_{2} \mathrm{O}_{2}$, and $200 \mu \mathrm{l}$ of the extract (Wang et al. 2020). CAT activity was measured by tracking the consumption of $\mathrm{H}_{2} \mathrm{O}_{2}$ at $240 \mathrm{~nm}(752 \mathrm{~S}$, Lengguang, Shanghai, China) for $3 \mathrm{~min}$. The soluble protein content (SP) was determined by the method as described by Bradford (1976). The extraction solution $(1 \mathrm{ml})$ was mixed with $5.0 \mathrm{ml}$ of Coomassie Brilliant Blue G-250 reagent, and placed at room temperature for $2 \mathrm{~min}$. Then the absorbance was measured at $595 \mathrm{~nm}$ by using a spectrophotometer $(722 \mathrm{~S}$, Lengguang, Shanghai, China), the content of soluble protein was calculated according to the standard curve of bovine serum protein.

Soluble sugar content (SS): The soluble sugar content in the extract was determined by anthrone colorimetry according to Dong et al. (2019). The fresh leaves of $0.05 \mathrm{~g}$ were transferred to tubes with $8.0 \mathrm{ml}$ of distilled water, and extracted twice in a boiling water for $30 \mathrm{~min}$. The extract was filtered and the volume was adjusted to $25 \mathrm{~mL}$ with distilled water. The extraction solution $(0.5 \mathrm{ml})$ was mixed with $1.5 \mathrm{~mL}$ of distilled water, $0.5 \mathrm{~mL}$ of ethyl anthrone acetate reagent, and $5 \mathrm{~mL}$ of concentrated sulfuric acid. Then the mixture in the test tube was placed in boiling water for $1 \mathrm{~min}$. After cooling to room temperature, the absorbance was measured at $630 \mathrm{~nm}$ (722S, Lengguang, Shanghai, China). Finally, the glucose calibration curve was established for the accurate quantification of soluble sugar.

The content of proline (Pro): Proline content was determined according to the methods of Bates et al. (1973). A sample of $0.25 \mathrm{~g}$ of leaf was transferred into the tube with $5 \mathrm{ml}$ of $3 \%$ sulfosalicylic acid solution, extracted in boiling water bath for $10 \mathrm{~min}$; then the supernatant was filtered and cooled to room temperature. The extract $(2 \mathrm{ml})$ was mixed with $2 \mathrm{ml}$ of acetic acid and $2 \mathrm{ml}$ of acid ninhydrin, and then the mixture was boiled for $30 \mathrm{~min}$. When cooled to room temperature, $4 \mathrm{ml}$ of toluene were added to the mixture. After shaking for $30 \mathrm{~s}$, the upper liquid was centrifuged at $3,000 \mathrm{rpm}$ for $5 \mathrm{~min}$. The absorbance was determined at $520 \mathrm{~nm}$ (722S, Lengguang, Shanghai, China) using toluene for a blank. The content of Pro in the sample was calculated according to the standard curve of Pro.

Relative electrical conductivity (REC): REC was evaluated by the method of Johal et al. (2020). Leaf samples $(0.1 \mathrm{~g})$ were washed with distilled water and then placed in tubes with $10 \mathrm{ml}$ of distilled water, kept at room temperature for $24 \mathrm{~h}$. The initial electrical conductivity (C1) was measured with a conductivity meter $(D D S-11 A$, Yoke Instrument, China). Then samples were boiled for $0.5 \mathrm{~h}$ at $100^{\circ} \mathrm{C}$. After cooling, the electrical conductivity was measured again (C2). REC was calculated as the percentage ratio of $(\mathrm{C} 2-\mathrm{C} 1) / \mathrm{C} 2$.

Malondialdehyde (MDA): MDA content was determined according to the method as described previously (Cai et al. 2019, Wu et al. 2021). The fresh leaves (0.25 g) were ground with $5 \mathrm{ml}$ of $5 \%(\mathrm{w} / \mathrm{v})$ trichloroacetic acid, and then centrifuged for $10 \mathrm{~min}$ at $3,000 \mathrm{rpm}$. The supernatant of $2 \mathrm{ml}$ was added to $2 \mathrm{ml}$ of $0.67 \%(\mathrm{w} / \mathrm{v}) \mathrm{TBA}$, boiled in water for $30 \mathrm{~min}$, and centrifuged for $10 \mathrm{~min}$ at 3,000 rpm again after cooling. Then, the absorbance of the mixture was measured at 450, 532, and $600 \mathrm{~nm}$ (722S, Lengguang, Shanghai, China).

Hydrogen peroxide $\left(\mathrm{H}_{2} \mathrm{O}_{2}\right)$ and superoxide $\operatorname{radical}\left(\mathrm{O}_{2}{ }^{--}\right)$: $\mathrm{H}_{2} \mathrm{O}_{2}$ content was determined according to Velikova et al. (2000). Leaf samples $(0.50 \mathrm{~g})$ were ground in $5 \mathrm{ml}$ of $1 \%$ trichloroacetic acid. The homogenates were centrifuged at $10,000 \mathrm{rpm}$ for $10 \mathrm{~min}$, then $0.20 \mathrm{ml}$ of supernatant was mixed with $0.5 \mathrm{ml}$ of $10 \mathrm{mM}$ phosphate buffer $(\mathrm{pH}$ 7.0) and $1 \mathrm{ml}$ of $1 \mathrm{M}$ iodide potassium, then stored in the dark for $20 \mathrm{~min}$. The mixture was centrifuged for $10 \mathrm{~min}$ at the speed of $10,000 \mathrm{rpm}$ at $4^{\circ} \mathrm{C}$, and the absorbance of 
the supernatant was read at $390 \mathrm{~nm}$ (752S, Lengguang, Shanghai, China). The $\mathrm{H}_{2} \mathrm{O}_{2}$ content was quantified using a calibration curve obtained with different concentrations of $\mathrm{H}_{2} \mathrm{O}_{2}$.

The superoxide radical $\left(\mathrm{O}_{2}{ }^{-}\right)$concentration was measured according to the method as described previously (Liu et al. 2016b). A sample of $1.0 \mathrm{~g}$ of leaf was homogenized in $5 \mathrm{~mL}$ of $65 \mathrm{mM}$ phosphate buffer ( $\mathrm{pH} 7.8$ ), filtered with four layers of gauze, and centrifuged at 1,000 rpm for $10 \mathrm{~min}$, then the supernatant was diluted to $10 \mathrm{ml}$. Later, $2 \mathrm{~mL}$ of extract was added to $1.5 \mathrm{~mL}$ of $65 \mathrm{mM}$ phosphate buffer ( $\mathrm{pH} 7.8$ ) and $0.5 \mathrm{~mL}$ of $10 \mathrm{mM}$ hydroxylamine hydrochloride, the mixture was kept in a water bath for $20 \mathrm{~min}$ at $25^{\circ} \mathrm{C}$. Two $\mathrm{ml}$ of the above mixture was added to a test tube containing $2 \mathrm{ml}$ of $7 \mathrm{mM}$ P-sulfanilic acid and $2 \mathrm{~mL}$ of $7 \mathrm{mM} \alpha$-naphthylamine, then incubated for 30 min at $30^{\circ} \mathrm{C}$. Finally, $\mathrm{O}_{2}^{-{ }^{-}}$content was determined by measuring the absorbance at $530 \mathrm{~nm}$ (722S, Lengguang, Shanghai, China).

Chl fluorescence: The Chl fluorescence parameters of the $3-4^{\text {th }}$ completely expanded leaves from the apex of tree peony were measured at 9:00-12:00 $\mathrm{h}$ in the morning by using a modulated fluorometer (Mini-PAM, Walz, Germany). The acting light, the flash, and the saturation pulse were set to 1,$000 ; 0.9$, and $>4,000 \mu \mathrm{mol}$ (photon) $\mathrm{m}^{-2} \mathrm{~s}^{-1}$, respectively. A dark treatment was conducted for $30 \mathrm{~min}$, then $\mathrm{F}_{0}, \mathrm{~F}_{\mathrm{m}}, \mathrm{F}_{\mathrm{v}} / \mathrm{F}_{\mathrm{m}}, \mathrm{F}_{0}{ }^{\prime}$, maximum fluorescence of the light-adapted state $\left(\mathrm{F}_{\mathrm{m}}{ }^{\prime}\right), \mathrm{F}_{\mathrm{v}}{ }^{\prime} / \mathrm{F}_{\mathrm{m}}{ }^{\prime}, \Phi_{\mathrm{PSII}}, \mathrm{q}_{\mathrm{P}}$, and ETR were then recorded according to the method of Genty et al. (1989).

The fraction of absorbed light energy was calculated according to the method of Demmig-Adams et al. (1996). The fraction of absorbed light energy used for PSII photochemistry $(\mathrm{P})$ was calculated as $\mathrm{P}=\mathrm{F}_{\mathrm{v}}{ }^{\prime} / \mathrm{F}_{\mathrm{m}}{ }^{\prime} \times \mathrm{q}_{\mathrm{P}}$, the light energy utilized in thermal dissipation (D) was estimated as $D=1-F_{v}{ }^{\prime} / F_{m}{ }^{\prime}$, the absorbed energy that is in excess of that which can be thermally dissipated or used in photochemistry $(\mathrm{E})$ was calculated from $\mathrm{E}=\mathrm{F}_{\mathrm{v}}{ }^{\prime} / \mathrm{F}_{\mathrm{m}}{ }^{\prime} \times$ $\left(1-q_{p}\right)$.

The Chl $a$ fluorescence transient (OJIP) and modulated 820-nm reflection transients: The $3-4^{\text {th }}$ leaves from the top in tree peony were used for determination at 9:00-11:00 $\mathrm{h}$ on a sunny day. The leaves were dark-adapted for at least $30 \mathrm{~min}$, and then the prompt $\mathrm{Chl}$ fluorescence induction kinetics curve (OJIP) and modulated $820-\mathrm{nm}$ reflection were simultaneously measured by M-PEA (Hansatech, Norfolk, UK). The OJIP curve was induced by saturated pulsed light with a light intensity of 3,000 $\mu$ mol(photon) $\mathrm{m}^{-2} \mathrm{~s}^{-1}$. The fluorescence signal was recorded from $10 \mu \mathrm{s}$ to $2 \mathrm{~s}$. The parameters of $\mathrm{Chl} a$ fluorescence transient (Appendix) were calculated by the JIP-test according to Strasser et al. (2010). The relative variable fluorescence was calculated as $\mathrm{V}_{\mathrm{t}}=\left(\mathrm{F}_{\mathrm{t}}-\mathrm{F}_{0}\right) /\left(\mathrm{F}_{\mathrm{m}}-\mathrm{F}_{0}\right), \Delta \mathrm{V}_{\mathrm{t}}=\mathrm{V}_{\mathrm{t} y l l}-\mathrm{V}_{\mathrm{tWT}}$, according to the method of Li et al. (2010a).

The modulated $820-\mathrm{nm}$ reflection transients in the leaves were induced by $250 \mu \mathrm{mol}\left(\right.$ photon) $\mathrm{m}^{-2} \mathrm{~s}^{-1}$ far-red light, and the measurement was performed on a clear day from 9:00 to 11:00 h. The 820-nm modulated reflection was expressed by $M R / \mathrm{MR}_{0} ; \mathrm{MR}_{0}$ is the light reflectance value of the initial illumination (taken from $0.7 \mathrm{~ms}$ in this study, the first credible MR measurement value), and MR is the light reflectance value of $820 \mathrm{~nm}$ during the illumination process (Liu et al. 2017). In this paper, the maximum redox activity of PSI was reflected by $\triangle \mathrm{I} / \mathrm{I}_{0}$, where $I_{0}$ is the average value of the $820-n m$ transmission signal between 0.4 and $10 \mathrm{~ms}$ and $\mathrm{I}_{\mathrm{m}}$ is the average of the 820 -nm transmission signal between 3 and $10 \mathrm{~s}$, while the following formula was used to calculate $\Delta \mathrm{I} / \mathrm{I}_{0}=\left(\mathrm{I}_{0}-\mathrm{I}_{\mathrm{m}}\right) / \mathrm{I}_{0}$, the coordination between PSI and PSII ( $\left.\Phi_{(\mathrm{PSI} / \mathrm{PSII})}\right)$, $\Phi_{(\mathrm{PSI} / \mathrm{PSII})}=\left(\triangle \mathrm{I} / \mathrm{I}_{0}\right) / \Psi_{0}$ (Strasser et al. 2004, Zhang et al. 2011).

Statistical analysis: All physiological parameters were measured with at least three biological replicates, while other parameters were measured with six biological replicates. The resulting data were analyzed by unpaired $t$-test in SPSS 13.0 (SPSS Inc., Chicago, IL, USA) for comparison at $P<0.05$ level.

\section{Results}

Differences in biochemical indexes: The activities of SOD and CAT, the contents of soluble protein, proline, MDA, $\mathrm{O}_{2}^{--}$and REC in yellow leaves of $y l 1$ mutant were significantly higher than those of WT plants (Table 1), while the soluble sugar content decreased greatly. The $\mathrm{H}_{2} \mathrm{O}_{2}$ content in $y l l$ mutant was higher than that in WT plant, but there were no significant differences between them.

Photochemical efficiency: The parameters of $F_{0}, F_{m}, F_{0}^{\prime}$, $\mathrm{F}_{\mathrm{m}}{ }^{\prime}, \mathrm{F}_{\mathrm{v}} / \mathrm{F}_{\mathrm{m}}, \mathrm{F}_{\mathrm{v}}{ }^{\prime} / \mathrm{F}_{\mathrm{m}}{ }^{\prime}, \Phi_{\mathrm{PSII}}$, and ETR all significantly decreased in yll mutant compared with those of the WT (Table 2), only $\mathrm{q}_{\mathrm{P}}$ showed no significant differences between two different leaf types.

Light absorption and distribution: The light energy absorbed by PSII can be divided into three parts, including the photochemical reaction $(\mathrm{P})$, the thermal dissipation (D), and excess absorbed light energy (E). The fraction of $\mathrm{P}$ and $\mathrm{E}$ in $y l 1$ mutant was greatly lower than those of WT plant (Fig. 1), while the fraction of D of $y l l$ mutant was significantly higher than that of WT.

The changes of prompt $\mathrm{Chl}$ fluorescence: The appearance of K-band is widely used as specific indicator of the damage of the oxygen-evolving complex (OEC) at the PSII donor side, while J- and I-band mainly reflect the activity of the PSII acceptor side (Kalaji et al. 2014). The relative fluorescence between the $\mathrm{O}$ - and P-steps were normalized $\left(\mathrm{V}_{\mathrm{t}}\right)$ and expressed as the kinetic differences $\left(\Delta \mathrm{V}_{\mathrm{t}}\right)$ to analyze the changes between $y l l$ mutant and WT plants (Fig. 2). All Chl $a$ fluorescence transient curves $\left(V_{t}\right)$ displayed a typical polyphasic rise with the basic steps of OJIP. OJIP curves from yll mutants showed a more obvious rise at the K-, J-, and I-step than those in WT plants (Fig. $2 A$ ). The $y l 1$ mutant showed positive $\Delta \mathrm{K}-, \Delta \mathrm{J}-$, and $\Delta \mathrm{I}$-bands around $300 \mu \mathrm{s}, 2 \mathrm{~ms}$, and $30 \mathrm{~ms}$ in respect 
Table 1. Biochemical parameters of the wild type and $y l l$ mutant. WT - wild type; $y l l-y l l$ mutant. ${ }^{*} P<0.05$ using $t$-test. CAT - catalase; MDA - malondialdehyde; Pro - proline; REC - relative electrical conductivity; SOD - superoxide dismutase; SP - soluble protein; SS - soluble sugar.

\begin{tabular}{llllllllll}
\hline Type & $\begin{array}{l}\text { SOD } \\
{\left[\mathrm{U} \mathrm{g}^{-1} \mathrm{~min}^{-1}\right]}\end{array}$ & $\begin{array}{l}\text { CAT } \\
{\left[\mathrm{U} \mathrm{g}^{-1} \mathrm{~min}^{-1}\right]}\end{array}$ & $\begin{array}{l}\mathrm{SP} \\
{\left[\mathrm{mg} \mathrm{g}^{-1}\right]}\end{array}$ & $\begin{array}{l}\text { SS } \\
{\left[\mathrm{mg} \mathrm{g}^{-1}\right]}\end{array}$ & \multicolumn{1}{l}{$\begin{array}{l}\text { Pro } \\
{\left[\mu \mathrm{g} \mathrm{ml}^{-1}\right]}\end{array}$} & $\begin{array}{l}\mathrm{REC} \\
{[\%]}\end{array}$ & $\begin{array}{l}\text { MDA } \\
{\left[\mathrm{nmol} \mathrm{g}^{-1}\right]}\end{array}$ & $\begin{array}{l}\mathrm{H}_{2} \mathrm{O}_{2} \\
{\left[\mu \mathrm{mol} \mathrm{g}^{-1}\right]}\end{array}$ & $\begin{array}{l}\mathrm{O}_{2}^{*} \\
{\left[\mu \mathrm{g} \mathrm{g}^{-1}\right]}\end{array}$ \\
\hline WT & $243.07 \pm 17.00$ & $23.81 \pm 5.98$ & $2.12 \pm 0.11$ & $15.04 \pm 0.93^{*}$ & $52.52 \pm 5.67$ & $42.33 \pm 3.52$ & $10.18 \pm 2.12$ & $63.91 \pm 5.04$ & $5.66 \pm 1.91$ \\
$y l l$ & $283.22 \pm 4.18^{*}$ & $36.66 \pm 6.84^{*}$ & $2.67 \pm 0.08^{*}$ & $7.05 \pm 0.83$ & $77.21 \pm 4.73^{*}$ & $52.61 \pm 2.15^{*}$ & $15.26 \pm 2.36^{*}$ & $70.67 \pm 1.07$ & $11.87 \pm 1.17^{*}$ \\
\hline
\end{tabular}

Table 2. Photochemical parameters of wild type and $y l l$ mutant. WT - wild type; $y l l-y l l$ mutant. ${ }^{*} P<0.05$ using $t$-test. ETR - electron transfer rate; $F_{0}{ }^{\prime}$ - minimal fluorescence yield of the light-adapted state; $F_{m}$ - maximal fluorescence yield of the dark-adapted state; $F_{m}{ }^{\prime}-$ maximal fluorescence yield of the light-adapted state; $F_{v} / F_{m}-$ maximal quantum yield of PSII photochemistry; $F_{v}{ }^{\prime} / F_{m}{ }^{\prime}-$ the efficiency of excitation capture of open PSII center; $\mathrm{q}_{\mathrm{P}}$ - photochemical quenching coefficient; $\Phi_{\mathrm{PSII}}-$ effective quantum yield of PSII photochemistry.

\begin{tabular}{|c|c|c|c|c|c|c|c|c|c|}
\hline Type & $\mathrm{F}_{0}$ & $\mathrm{~F}_{\mathrm{m}}$ & $\mathrm{F}_{0}^{\prime}$ & $\mathrm{F}_{\mathrm{m}}{ }^{\prime}$ & $\mathrm{F}_{\mathrm{v}} / \mathrm{F}_{\mathrm{m}}$ & $\mathrm{F}_{\mathrm{v}}{ }^{\prime} / \mathrm{F}_{\mathrm{m}}{ }^{\prime}$ & $\Phi_{\text {PSII }}$ & $\mathrm{q}_{\mathrm{P}}$ & ETR \\
\hline WT & $346.75 \pm 39.55^{*}$ & ${ }^{*} 1,318.25 \pm 212.98^{*}$ & $244.13 \pm 14.05^{*}$ & ${ }^{*} 513.67 \pm 60.30^{*}$ & $0.73 \pm 0.03^{*}$ & $0.52 \pm 0.05^{*}$ & ${ }^{*} 0.43 \pm 0.03^{*}$ & $0.82 \pm 0.03$ & $34.05 \pm 2.50^{*}$ \\
\hline$y l l$ & $233.00 \pm 4.24$ & $428.00 \pm 31.11$ & $177.67 \pm 0.47$ & $270.33 \pm 16.97$ & $0.45 \pm 0.05$ & $0.35 \pm 0.04$ & $0.29 \pm 0.02$ & $0.84 \pm 0.05$ & $23.02 \pm 1.41$ \\
\hline
\end{tabular}

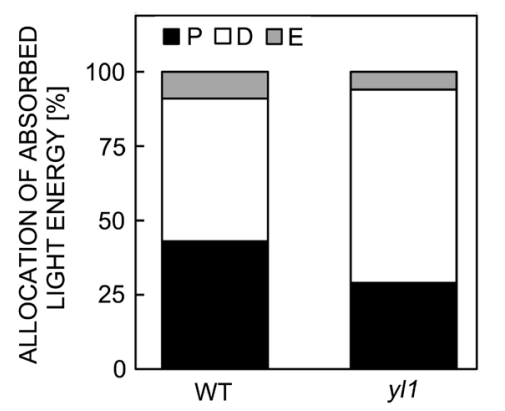

Fig. 1. Allocation of absorbed light energy in wild type and yll mutant. P - the light energy used for PSII photochemistry; D the light energy utilized in thermal dissipation; E - the absorbed energy that is in excess of that which can be thermally dissipated or used in photochemistry. WT - wild type; $y l l-y l l$ mutant.

to WT plant (Fig. 2B). In order to quantify changes in the K-, J-, and I-steps in the OJIP curves, the normalized relative variable fluorescence at the $\mathrm{K}$-step $\left(\mathrm{W}_{\mathrm{K}}\right)$, and the relative variable fluorescence at the J-step $\left(\mathrm{V}_{\mathrm{J}}\right)$ and I-step $\left(\mathrm{V}_{\mathrm{I}}\right)$ were calculated (Fig. 3). The value of $\mathrm{W}_{\mathrm{K}}, \mathrm{V}_{\mathrm{J}}$, and $\mathrm{V}_{\mathrm{I}}$ in yll mutants all increased markedly compared to those of WT plants. The increase of $\mathrm{V}_{\mathrm{J}}$ was more obvious in $y l l$ mutants than that in $\mathrm{W}_{\mathrm{K}}$ and $\mathrm{V}_{\mathrm{I}}$, while the increase of $\mathrm{W}_{\mathrm{K}}$ was greater than that in $\mathrm{V}_{\mathrm{I}}$.

The parameters of $\mathrm{M}_{0}, \Psi_{0}, \varphi \mathrm{E}_{0}$, and $\mathrm{S}_{\mathrm{M}}$ mainly reflect the changes of PSII acceptor side ( $\mathrm{Li}$ et al. 2005). The value of $\mathrm{M}_{0}$ in $y l l$ mutant was significantly higher than that of WT plant (Table 3), while the values of $\Psi_{0}$ and $\varphi \mathrm{E}_{0}$ of $y l 1$ mutant were greatly lower than those of WT plant. The value of $\mathrm{S}_{\mathrm{m}}$ in $y l l$ mutant was also lower than that of the WT plant.

The values of $\mathrm{ABS} / \mathrm{RC}, \mathrm{TR}_{0} / \mathrm{RC}$, and $\mathrm{DI}_{0} / \mathrm{RC}$ in $y l l$ mutant were significantly higher than those of WT plant (Fig. 4), while $\mathrm{ET}_{0} / \mathrm{RC}$ was much lower in the $y l 1$ mutant than that of WT plant. As shown in Fig. 4, the values of $\mathrm{RC} / \mathrm{CS}_{0}, \mathrm{ABS} / \mathrm{CS}_{0}, \mathrm{TR}_{0} / \mathrm{CS}_{0}, \mathrm{ET}_{0} / \mathrm{CS}_{0}$, and $\mathrm{PI}_{\mathrm{ABS}}$ of $y l l$

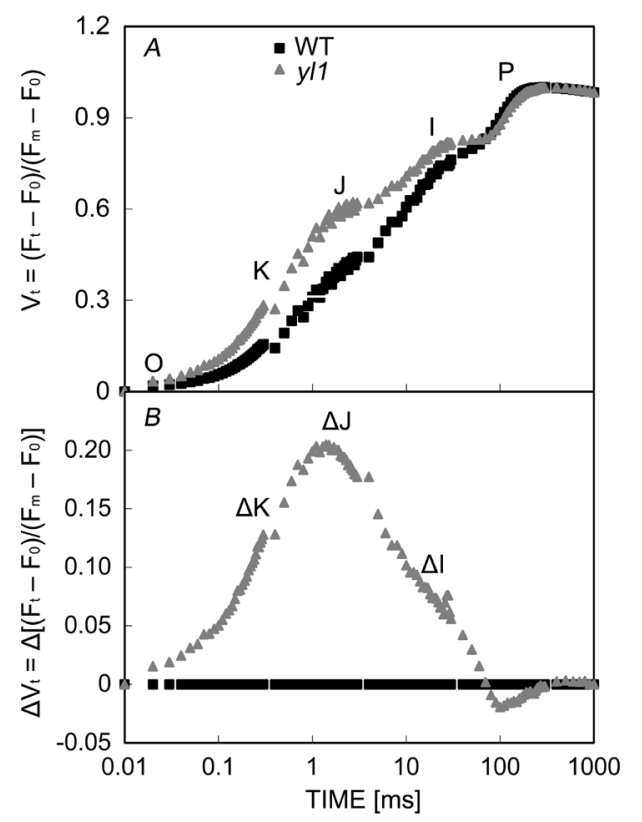

Fig. 2. Changes in the shape of the chlorophyll $a$ fluorescence transient curves of wild type and $y l l$ mutant. Chl $a$ fluorescence transients were normalized between $\mathrm{F}_{0}$ to $\mathrm{F}_{\mathrm{p}}$ : $\mathrm{V}_{\mathrm{t}}=\left(\mathrm{F}_{\mathrm{t}}-\mathrm{F}_{0}\right) /$ $\left(\mathrm{F}_{\mathrm{m}}-\mathrm{F}_{0}\right)(A) ; \Delta \mathrm{V}_{\mathrm{t}}$ was the difference of $\mathrm{V}_{\mathrm{t}}$ between $y l l$ mutant and wild type plant in tree peony: $\Delta \mathrm{V}_{\mathrm{t}}=\mathrm{V}_{\mathrm{t} y l l}-\mathrm{V}_{\mathrm{t}}$ wT $(B)$. WT - wild type; $y l l-y l l$ mutant.

mutant all significantly decreased than those of WT plant. The value of $\mathrm{DI}_{0} / \mathrm{CS}_{0}$ of $y l l$ mutant was lower than that of WT but the difference was not significant.

The changes in PSI: The 820 -nm curve of $y l l$ mutant changed significantly compared with the control, and its lowest point of its $\mathrm{MR} / \mathrm{MR}_{0}$ greatly increased (Fig. 5). The $\Delta \mathrm{I} / \mathrm{I}_{0}$ of $y l 1$ mutant was significantly lower than that of WT plant. 


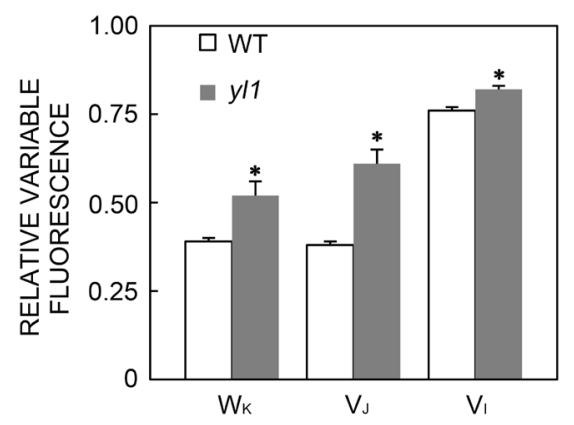

Fig. 3. The changes of relative variable fluorescence of wild type and $y l l$ mutant. $\mathrm{W}_{\mathrm{K}}$ - normalized relative variable fluorescence at the K-step; $\mathrm{V}_{\mathrm{J}}$ and $\mathrm{V}_{\mathrm{I}}$ - relative variable fluorescence at the J- and I-step; WT - wild type; $y l l-y l l$ mutant. ${ }^{*}$ - significant differences between WT and $y l l$ mutant $(P<0.05)$.

Table 3. Changes of chlorophyll $a$ fluorescence transient of wild type and $y l l$ mutant. WT - wild type; $y l l-y l l$ mutant. ${ }^{*} P<0.05$ using $t$-test. $\mathrm{M}_{0}$ - the initial slope of the relative variable fluorescence of the relative rate at which $\mathrm{Q}_{\mathrm{A}}$ is reduced; $\mathrm{S}_{\mathrm{m}}-$ normalized total complementary area above the OJIP transient; $\varphi \mathrm{E}_{0}-$ quantum yield for electron transport $($ at $\mathrm{t}=0) ; \Psi_{0}-$ probability that a trapped exciton moves an electron into the electron transport chain beyond $\mathrm{Q}_{\mathrm{A}}^{-}($at $\mathrm{t}=0)$.

\begin{tabular}{lllll}
\hline Type & $\mathrm{M}_{0}$ & $\Psi_{0}$ & $\varphi \mathrm{E}_{0}$ & $\mathrm{~S}_{\mathrm{m}}$ \\
\hline WT & $0.59 \pm 0.01$ & $0.62 \pm 0.01^{*}$ & $0.48 \pm 0.01^{*}$ & $28.24 \pm 0.25$ \\
$y l 1$ & $1.28 \pm 0.17^{*}$ & $0.39 \pm 0.04$ & $0.27 \pm 0.01$ & $24.29 \pm 2.00$ \\
\hline
\end{tabular}

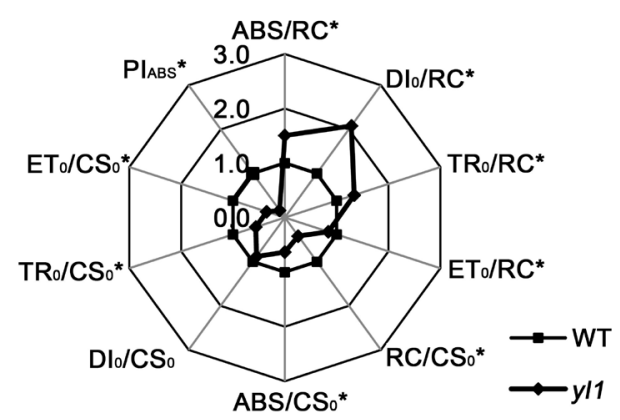

Fig. 4. The energy fluxes and performance index $\left(\mathrm{PI}_{\mathrm{ABS}}\right)$ of wild type and $y l l$ mutant. WT - wild type; $y l l-y l l$ mutant. * - significant differences between WT and $y l l$ mutant $(P<0.05)$; all the values in $y l l$ mutant were expressed relative to WT plants (set as 1). $\mathrm{ABS} / \mathrm{CS}_{0}$ - absorption flux per CS (at $\mathrm{t}=0$ ); $\mathrm{ABS} / \mathrm{RC}$ absorption flux per reaction center $(\mathrm{RC}) ; \mathrm{DI}_{0} / \mathrm{CS}_{0}$ - dissipated energy flux per $\mathrm{CS}($ at $\mathrm{t}=0) ; \mathrm{DI}_{0} / \mathrm{RC}$ - dissipated energy flux per $\mathrm{RC}($ at $\mathrm{t}=0) ; \mathrm{ET}_{0} / \mathrm{CS}_{0}$ - electron transport flux per $\mathrm{CS}$ (at $\mathrm{t}=0) ; \mathrm{ET}_{0} / \mathrm{RC}$ - electron transport flux per $\mathrm{RC}($ at $\mathrm{t}=0$ ); $\mathrm{RC} / \mathrm{CS}_{0}$ - density of RCs per excited cross-section (CS) (at t $=0$ ); $\mathrm{TR}_{0} / \mathrm{CS}_{0}$ - trapped energy flux per $\mathrm{CS}($ at $\mathrm{t}=0) ; \mathrm{TR}_{0} / \mathrm{RC}$ - trapped energy flux per $\mathrm{RC}($ at $\mathrm{t}=0$ ).

The ratio of $\triangle \mathrm{I} / \mathrm{I}_{0}$ to $\Psi_{0}$ can represent the coordination between PSI and PSII (Li et al. 2010b). The value of
$\Phi_{\text {(PSI/PSII) }}$ of the $y l l$ mutant was significantly lower than that of WT plant (Fig. 6), which indicated that the coordination between two photosystems of $y l l$ mutant was reduced.

\section{Discussion}

Excessive ROS generation can promote phospholipid peroxidation, destroy cell membrane, and increase the penetration of intracellular electrolytes. MDA content is considered to be an important indicator of lipid peroxidation level. Leaf-color mutants were susceptible to photooxidative stress and some showed severe membrane lipid peroxidation and electrolyte leakage (Li 2016). In this study, the significant increase of MDA content and REC of $y l l$ mutant suggested that it suffered severe photooxidation of the cell membrane and electrolyte leakage, which was also confirmed by the obvious increase of $\mathrm{H}_{2} \mathrm{O}_{2}$ and $\mathrm{O}_{2}{ }^{-}$ contents in the $y l l$ mutant. In addition, ROS can directly destroy the PSII reaction center (Krieger-Liszkay et al. 2011), hinder the repair of PSII, and aggravate the photoinhibition damage by inhibiting the synthesis of D1 protein in the photosystem (Takahashi and Murata 2008). Our results confirmed these findings, as $y l l$ mutant plant showed a lower $\mathrm{RC} / \mathrm{CS}_{0}$ and $\mathrm{F}_{\mathrm{v}} / \mathrm{F}_{\mathrm{m}}$.

In order to resist oxidative damage by ROS, the antioxidant enzymes can catalyze ROS detoxification (Labudda et al. 2020). The $y l 1$ mutant could reduce the damage caused by ROS by increasing activities of SOD and CAT and enhance the ability of osmotic regulation by increasing the contents of soluble protein and Pro. This study was consistent with previous studies on leaf color mutants of melon (Cucumis melo) (Lai et al. 2018) and cucumber (Cucumis sativus) (Li et al. 2015). It is well known that SOD catalyzes the conversion of $\mathrm{O}_{2}{ }^{-}$to $\mathrm{H}_{2} \mathrm{O}_{2}$, and $\mathrm{H}_{2} \mathrm{O}_{2}$ can be eliminated by CAT (Labudda et al. 2020). The yellow leaves of $y l l$ mutant could improve SOD and CAT activities to scavenge ROS and protect the photosystems; similar studies also appeared in the albino tissue of Hibotan-nishiki cactus (Gymnocalycium mihanovichii) (Deng 2009). In this study, the increase of $\mathrm{O}_{2}{ }^{-}$content was higher than that of $\mathrm{H}_{2} \mathrm{O}_{2}$ in the $y l l$ mutant, which was similar to the results of the rice (Oryza sativa) zebra-leaf mutant $l 139$ (Guo 2020); such results might be observed because the increase of CAT activity was higher than that of SOD activity.

Soluble sugar is one of the main storage substances of the energy metabolism in plants. In this study, the decrease of soluble sugar content in $y l l$ mutant might occur due to the decline of PSII and PSI functions and lower photosynthetic rate (Chang et al. 2019). This study was consistent with that of rice (Oryza sativa) yellow-leaf mutant (Hu 2017) and yellow-leaf mutant rgm (1-20YY) in common wheat (Triticum aestivum) (Liu et al. 2016a). Soluble proteins are important osmotic adjustment substances and nutrients, most of which are enzymes involved in metabolism (Li 2016). Previous studies have shown that the soluble sugar contents of cucumber (Cucumis sativus) and anthurium (Anthurium andraeanum) leaf-color mutants were lower than those of the control, but the soluble protein contents were higher than those of the control (Chen 2009, Li 2016), 


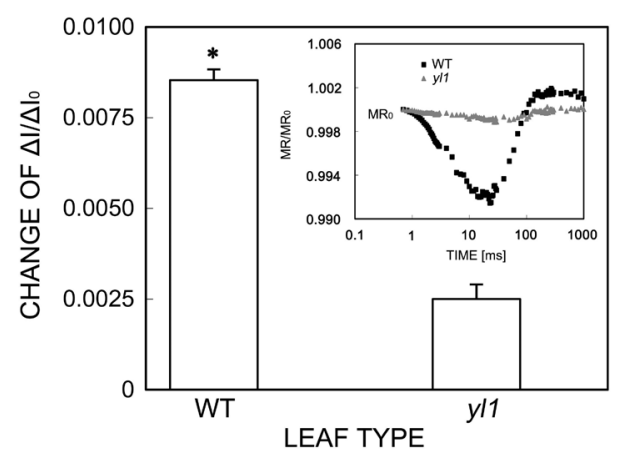

Fig. 5. The changes of modulated $820-\mathrm{nm}$ reflection curves and maximum PSI redox activity of the wild type and $y l l$ mutant. WT - wild type; $\mathrm{MR}_{0}$ - the light reflectance value of the initial illumination; MR - the light reflectance value of $820 \mathrm{~nm}$ during the illumination process; WT - wild type; $y l l-y l l$ mutant. ${ }^{*}$ - significant differences between WT and $y l l$ mutant $(P<0.05)$.

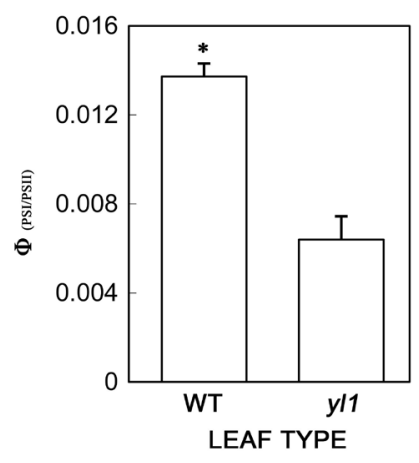

Fig. 6. Changes of coordination between PSI and PSII ( $\left.\Phi_{(\text {PSIPSII) }}\right)$ of the wild type and $y l l$ mutant. WT - wild type; $y l l-y l l$ mutant. * - significant differences between WT and yll mutant $(P<0.05)$.

which was similar to this study. It was speculated that the specific expression of some genes in the leaves of the mutants increased, which led to an increase of the soluble protein content (Li 2016). The increase of Pro content in yll mutant could maintain cell turgor, prevent electrolyte leakage, and reduce the damage by ROS (Rastogi et al. 2020), which was consistent with previous studies on the light-green leaf mutant in Sorghum bicolor (Zhang et al. 2014).

The decrease of $\mathrm{F}_{0}, \mathrm{~F}_{\mathrm{m}}, \mathrm{F}_{0}{ }^{\prime}$, and $\mathrm{F}_{\mathrm{m}}{ }^{\prime}$ in $y l l$ mutant showed a reduction of light energy capture efficiency and utilization in PSII reaction center. The lower values of $F_{v} /$ $\mathrm{F}_{\mathrm{m}}, \mathrm{F}_{\mathrm{v}}{ }^{\prime} / \mathrm{F}_{\mathrm{m}}{ }^{\prime}, \Phi_{\mathrm{PSII}}$, and ETR of $y l l$ mutant indicated that the light energy-utilization efficiency decreased in yll mutant (Xiao et al. 2013, Yang et al. 2014), which was consistent with the photosynthetic rate of $y l l$ mutant measured previously (Chang et al. 2019). There was no significant difference in $\mathrm{q}_{\mathrm{P}}$ between $y l l$ mutant and WT, which might imply that the reduction of Chl content did not necessarily have a significant effect on photochemical quenching. This study was consistent with leaf-color mutants in Brassica rapa (Liu et al. 2014) and Pseudosasa japonica (Chen et al. 2018).
The fraction of $\mathrm{P}$ significantly decreased which could reduce the load of PSII reaction center. The increase of the proportion of $\mathrm{D}$ implied the excess light energy could be dissipated by thermal dissipation, thus protecting photosynthetic apparatus (Yang et al. 2009). The significant reduction of $\mathrm{E}$ could not only reduce the excitation pressure of PSII and the formation of superoxide radical but also reduce the reversible deactivation or destruction of the photosystems (Hu et al. 2005). The changes of $\mathrm{D}$ and $\mathrm{E}$ might indicate that $y l l$ mutant had the ability to avoid oxygen stress.

The K-steps on the OJIP curve raised greatly in the $y l l$ mutant, which indicated that the OEC on the donor side of PSII had been severely damaged (Parmoon et al. 2019). The increase of J-steps showed that the acceptor side of $y l 1$ mutant was also injured; the increase of phase $\mathrm{J}$ was higher than that of phase $\mathrm{K}$, indicating that the damage on the acceptor side was significantly higher than that of donor side.

In this study, the lower value of $\varphi \mathrm{E}_{0}$ in the $y l 1$ mutant indicated that the relative electron transfer ability decreased. The increase of $\mathrm{M}_{0}$ and $\mathrm{V}_{\mathrm{J}}$ indicated that the reduction rate of $\mathrm{Q}_{\mathrm{A}}$ was accelerated, the electron transfer from PSII acceptor side $\mathrm{Q}_{\mathrm{A}}$ to secondary quinone receptor $\left(\mathrm{Q}_{\mathrm{B}}\right)$ was blocked, resulting in the accumulation of $\mathrm{Q}_{\mathrm{A}}^{-}$in $y$ ll mutant ( $\mathrm{Li}$ et al. 2005). The increase in $\mathrm{V}_{\mathrm{I}}$ steps on the OJIP curve in $y l l$ mutant indicated that the electron transfer from $\mathrm{Q}_{\mathrm{B}}$ to the downstream was further blocked. The decrease in $S_{m}$ indicated that the PQ pool of the electron acceptor of PSII was reduced, and the number of the electron transporters accepted by the acceptor side of PSII was reduced, which led to a decrease in $\varphi \mathrm{E}_{0}$ and $\Psi_{0}$.

A significant increase of $\mathrm{ABC} / \mathrm{RC}$ and $\mathrm{TR}_{0} / \mathrm{RC}$ reflected that the $y l l$ mutant could increase the ability of light absorption and capture of a single reaction center and promote the efficiency improvement of the remaining active reaction centers, thus making up for the deficiency of $y$ ll mutant in the number of reaction centers, which might be a compensation mechanism. The decline in $\mathrm{ET}_{0} / \mathrm{RC}$ of yellow leaves showed that the quantum share of yellow leaves used for electron transport was reduced, which was in agreement with the significant decrease of ETR. The ABS/RC and $\mathrm{TR}_{0} / \mathrm{RC}$ in $y l l$ mutant increased greatly, while the $\mathrm{ET}_{0} / \mathrm{RC}$ decreased significantly, which indicated that the weakening of the dynamics of electron transport from OEC to PSII, and a large amount of electrons accumulated at the $\mathrm{Q}_{\mathrm{A}}$ side (Souza et al. 2019). A marked increase in $\mathrm{DI}_{0} / \mathrm{RC}$ of $y l l$ mutant indicated a loss of absorbed excitation energy as heat and fluorescence rather than photochemistry, which was consistent with the higher proportion of thermal dissipation (D).

The significant decrease of $\mathrm{RC} / \mathrm{CS}_{0}, \mathrm{ABS} / \mathrm{CS}_{0}, \mathrm{TR} / \mathrm{CS}_{0}$, and $\mathrm{ET} / \mathrm{CS}_{0}$ suggested that there was a large amount of energy accumulation in $y l l$ mutant, which would increase ROS content and damage OEC (Li et al. 2009).

Although the utilization capacity of light energy per reaction center increased, the improvement of the efficiency per reaction center could not compensate for the decrease of the number of active centers per excited cross-section $\left(\mathrm{RC} / \mathrm{CS}_{0}\right)$, which led to the decrease in the 
utilization rate of light energy per excited cross-section ( $\mathrm{Li}$ et al. 2009), and finally resulted in a significant decline in $\mathrm{PI}_{\mathrm{ABS}}$ of $y l l$ mutant. In this study, the decrease of $\varphi \mathrm{E}_{0}$ and the increase of $\mathrm{V}_{\mathrm{J}}, \mathrm{V}_{\mathrm{I}}$, and $\mathrm{M}_{0}$ indicated that the PSII reaction center of $y l l$ mutant was inactivated and electron transfer of PSII was blocked, which made yellow leaves of yll mutant more susceptible to photoinhibition, resulting in a significant decrease of $\mathrm{F}_{\mathrm{v}} / \mathrm{F}_{\mathrm{m}}$.

$\mathrm{MR} / \mathrm{MR}_{0}$ represents the redox state of $\mathrm{P}_{700}$ and plastocyanin (PC) (Sun et al. 2017). The increase in the lowest point of $\mathrm{MR} / \mathrm{MR}_{0}$ of the $y l l$ mutant showed that the oxidation rate of $\mathrm{P}_{700}$ and $\mathrm{PC}$ slowed down, which indicated that the amount of electrons transferred to $\mathrm{P}_{700}{ }^{+}$decreased. The parameter of $\Delta \mathrm{I} / \mathrm{I}_{0}$ represents the performance of PSI. The significant decrease in $\Delta \mathrm{I} / \mathrm{I}_{0}$ of $y l l$ mutant showed that the function of PSI was weakened. The changes of $\Delta \mathrm{I} / \mathrm{I}_{0}$ and $\mathrm{F}_{\mathrm{v}} / \mathrm{F}_{\mathrm{m}}$ can be used to estimate the photoinhibition of PSI and PSII, respectively (Guo et al. 2018). The reduction of $\Delta \mathrm{I} / \mathrm{I}_{0}$ and $\mathrm{F}_{\mathrm{v}} / \mathrm{F}_{\mathrm{M}}$ indicated that PSI and PSII of $y l l$ mutant were photoinhibited in different degrees. $\mathrm{F}_{0}$ can be regarded as a reliable indicator of PSI/PSII ratio (Pfündel et al. 2013). A significant decrease in $\mathrm{F}_{0}$ indicated a reduction of PSI/PSII ratio in the $y l l$ mutant, which would result in an imbalance between the two photosystems (Brestic et al. 2015). The reduction in the activities of PSI and PSII and the imbalance of PSI/PSII in the $y l l$ mutant would reduce the efficiency of the electron transport chain after $\mathrm{Q}_{\mathrm{A}}$, block the electron flow from PSI, aggravate photoinhibition, and produce a large amount of ROS (Liu et al. 2018), which was confirmed by the increase of ROS in yll mutant.

In summary, the obvious rise of the $\mathrm{K}-, \mathrm{J}-$, and I-steps of the OJIP curves indicated that OEC of $y l l$ mutant was damaged and the electron transfer of PSII was blocked, which further affected the electron transfer to PSI. Due to the different degree of photoinhibition of these two photosystems, the activities of PSI and PSII decreased, accompanied by an imbalance of PSI/PSII, which ultimately led to the decline of $\mathrm{PI}_{\mathrm{ABS}}$ of $y l l$ mutant. As the electron transfer from PSII to PSI was blocked, $y l l$ mutant produced a lot of ROS, which led to the increase of REC and MDA. The $y l l$ mutant could reduce the damage of ROS by increasing the activity of antioxidant enzymes and the contents of some osmotic adjustment substances and reduce the damage caused by excessive light energy by increasing the proportion of heat dissipation.

\section{References}

Bates L.S., Waldren R.P., Teare I.D.: Rapid determination of free proline for water-stress studies. - Plant Soil 39: 205-207, 1973.

Bradford M.M.: A rapid and sensitive method for the quantitation of microgram quantities of protein utilizing the principle of protein-dye binding. - Anal. Biochem. 72: 248-254, 1976.

Brestic M., Zivcak M., Kunderlikova K. et al.: Low PSI content limits the photoprotection of PSI and PSII in early growth stages of chlorophyll $b$-deficient wheat mutant lines. Photosynth. Res. 125: 151-166, 2015.

Cai H., Xie P., Zeng W. et al.: Root-specific expression of rice OSHMA3 reduces shoot cadmium accumulation in transgenic tobacco. - Mol. Breeding 39: 49, 2019.

Chai C., Fang J., Liu Y. et al.: ZEBRA2, encoding a carotenoid isomerase, is involved in photoprotection in rice. - Plant Mol. Biol. 75: 211-221, 2011.

Chang Q.S., Zhang L.X., Hou X.G. et al.: The anatomical, physiological and molecular analysis of a chlorophylldeficient mutant in tree peony (Paeonia suffruticosa). Photosynthetica 57: 724-730, 2019.

Chen K.Y., Li C.N., Cheng M.M. et al.: [Chloroplast ultrastructure and chlorophyll fluorescence characteristics of three cultivars of Pseudosasa japonica.] - Chin. Bull. Bot. 53: 509-518, 2018. [In Chinese]

Chen L., Yuan Q.Z.: [Study on Luoyang tourism climate comfort based on entropy method.] - J. Luoyang Normal Univ. 37: 20-25, 2018. [In Chinese]

Chen X.X.: [Formative mechanism and maintenance characteristics of leaf color chimera and mutants of Anthurium andreaeanum 'Sonate'.] Master Thesis. Nanjing Agricultural University, Nanjing 2009. [In Chinese]

Chu J.T.: [Study on leaf color variation mechanism of a new cultivar 'Golden qilu' in Acer buergerianum Miq.] Master Thesis. Shandong Agricultural University, Taian 2020. [In Chinese]

Dąbrowski P., Kalaji M.H., Baczewska A.H. et al.: Delayed chlorophyll a fluorescence, MR 820, and gas exchange changes in perennial ryegrass under salt stress. - J. Lumin. 183: 322-333, 2017.

Dąbrowski P., Pawluśkiewicz B., Baczewska A.H. et al.: Chlorophyll $a$ fluorescence of perennial ryegrass (Lolium perenne L.) varieties under long term exposure to shade. Zemdirbyste 102: 305-312, 2015.

Demmig-Adams B., Adams III W.W., Barker D.H. et al.: Using chlorophyll fluorescence to assess the fraction of absorbed light allocated to thermal dissipation of excess excitation. Physiol. Plantarum 98: 253-264, 1996.

Deng B.L.: [Albino plant and higher endogenous reactive oxygen species toxicity.] Master Thesis. Lanzhou University, Lanzhou 2009. [In Chinese]

Dong F., Wang C., Sun X. et al.: Sugar metabolic changes in protein expression associated with different light quality combinations in tomato fruit. - Plant Growth Regul. 88: 267282, 2019.

Du Q., Wang N., Zhao X.H. et al.: [Effects of potassium deficiency on photosynthesis and performance of photosystem II in maize seedling stage.] - J. Nucl. Agric. Sci. 33: 592-599, 2019. [In Chinese]

Genty B., Briantais J.M., Baker N.R.: The relationship between the quantum yield of photosynthetic electron transport and quenching of chlorophyll fluorescence. - BBA-Gen. Subjects 990: 87-92, 1989.

Guo N.H.: [Gene mapping and physiological characteristics analysis of a zebra leaf mutant 1139 in rice.] Master Thesis. Shenyang Agricultural University, Shenyang 2020. [In Chinese]

Guo Y.Y., Tian S.S., Liu S.S. et al.: Energy dissipation and antioxidant enzyme system protect photosystem II of sweet sorghum under drought stress. - Photosynthetica 56: 861-872, 2018.

Hu W.H., Xiao Y.A., Yu J.Q. et al.: [Effects of different light intensity after low night temperature stress on PSII functions and absorbed light allocation in leaves of Ficus macrocarpa.] Bull. Bot. Res. 25: 159-162, 2005. [In Chinese]

$\mathrm{Hu} \mathrm{Z}$.: [Gene cloning and functional analysis of $y l l$ conferring the leaf color through characterizing the rice $y l l$ mutant.] Master Thesis. Yangzhou university, Yangzhou 2017. [In Chinese]

Johal N., Kaur J., Grewal S.K. et al.: Physiological and bio- 
chemical responses of chickpea accessions at reproductive stage under receding moisture conditions. - Agr. Res. 9: 554567,2020 .

Kalaji H.M., Schansker G., Brestic M. et al.: Frequently asked questions about chlorophyll fluorescence, the sequel. Photosynth. Res. 132: 13-66, 2017.

Kalaji H.M., Schansker G., Ladle R.J. et al.: Frequently asked questions about in vivo chlorophyll fluorescence: Practical issues. - Photosynth. Res. 122: 121-158, 2014.

Krieger-Liszkay A., Kós P.B., Hideg E.: Superoxide anion radicals generated by methylviologen in photosystem I damage photosystem II. - Physiol. Plantarum 142: 17-25, 2011.

Labudda M., Tokarz K., Tokarz B. et al.: Reactive oxygen species metabolism and photosynthetic performance in leaves of Hordeum vulgare plants co-infested with Heterodera filipjevi and Aceria tosichella. - Plant Cell Rep. 39: 1719-1741, 2020.

Lai Y., Fu Q.S., Lv J.C. et al.: [Analysis of physiological characteristics and chloroplast ultrastructure of a new leaf color mutant in melon.] - J. Sichuan Agric. Univ. 36: 372379, 2018. [In Chinese]

Li G., Gao H.Y., Liu P. et al.: [Effects of nitrogen fertilization on photosynthetic performance in maize leaf at grain filling stage.] - Plant Nutr. Fert. Sci. 16: 536-542, 2010 b. [In Chinese]

Li G., Gao H.Y., Zhao B. et al.: [Effects of drought stress on activity of photosystems in leaves of maize at grain filling stage.] - Acta Agron. Sin. 35: 1916-1922, 2009. [In Chinese]

Li P.M., Gao H.Y., Strasser R.J.: [Application of the fast chlorophyll fluorescence induction dynamics analysis in photosynthesis study.] - J. Plant Physiol. Mol. Biol. 31: 559566, 2005. [In Chinese]

Li Q., Chen L.S., Jiang H.X. et al.: Effects of manganese-excess on $\mathrm{CO}_{2}$ assimilation, ribulose-1,5-bisphosphate carboxylase/ oxygenase, carbohydrates and photosynthetic electron transport of leaves, and antioxidant systems of leaves and roots in Citrus grandis seedlings. - BMC Plant Biol. 10: 42, 2010a.

Li W.Q., Gao B., Yang J. et al.: [Physiological characteristic analysis of a new leaf color yellow mutant in cucumber.] Acta Agric. Bor.-Occident. Sin. 24: 98-103, 2015. [In Chinese]

Li X., Brestic M., Tan D.X. et al.: Melatonin alleviates low PS Ilimited carbon assimilation under elevated $\mathrm{CO}_{2}$ and enhances the cold tolerance of offspring in chlorophyll $b$-deficient mutant wheat. - J. Pineal Res. 64: e12453, 2018.

Li Y.: [Physiological characteristics and genetic analysis of leaf color mutant in cucumber.] Master Thesis. Sichuan Agricultural University, Chendu 2016. [In Chinese]

Liu A.R., Wang M.M., Liu D.L. et al.: Arbuscular mycorrhizal fungus alleviates chilling stress by boosting redox poise and antioxidant potential of tomato seedlings. - J. Plant Growth Regul. 35: 109-120, 2016b.

Liu C., Duan Y., An X. et al.: [Comparison of main physiological characteristics, chloroplast morphology and ultra-structure of the yellow-green wheat (Triticum aestivum) near-isogenic lines.] - J. Agric. Biotech. 24: 806-814, 2016a. [In Chinese]

Liu J., Yang Y.H., Hao Y.C. et al.: [Effects of photosynthetic electron transport chain of maize leaves under drought stress and re-watering.] - Plant Physiol. J. 53: 1877-1884, 2017. [In Chinese]

Liu M.J., Sui X.Q., An S.Z.: [The effect of dehydration on Cynodon dactylon L. leaf photosynthetic apparatus.] - Acta Agr. Sin. 26: 441-446, 2018. [In Chinese]

Liu M.Y., Lu Y., Zhao J.J. et al.: [HRM identification and chlorophyll fluorescence characteristics on leaf color mutants in chinese cabbage.] - Acta Hortic. Sin. 41: 2215-2224, 2014.
[In Chinese]

Lv D.H.: [Study on photosynthetic, physiological and biochemical characteristics in leaf color mutants of rice (Oryza sativa L.).] Master Thesis. Southwest University, Chongqing 2010. [In Chinese]

Parmoon G., Ebadi A., Jahanbakhsh S. et al.: Assessing photosynthetic performance of fennel (Foeniculum vulgare Mill) influenced by plant growth regulators and drought stress imposed at vegetative and reproductive stages. - Ital. J. Agron. 14: 93-100, 2019.

Pfündel E.E., Klughammer C., Meister A., Cerovic Z.G.: Deriving fluorometer-specific values of relative PSI fluorescence intensity from quenching of $F_{O}$ fluorescence in leaves of Arabidopsis thaliana and Zea mays. - Photosynth. Res. 114: 189-206, 2013.

Qiu N.W., Zhou F., Wang Y. et al.: [Comparison on characteristics of the fast chlorophyll fluorescence induction kinetics between Pinus species and Populus species.] - Sci. Silva. Sin. 49: 136143, 2013. [In Chinese]

Rastogi A., Kovar M., He X. et al.: JIP-test as a tool to identify salinity tolerance in sweet sorghum genotypes. Photosynthetica 58: 518-528, 2020.

Ru G.X., Liu X.N., Zhu X.H. et al.: [Physiological characteristic analysis of etiolation mutant in Paulownia fortnnei.] J. Nanjing Forest. Univ. 60: 181-185, 2017. [In Chinese]

Souza A.F.C, Martins J.P.R., Gontijo A.B.P.L., Falqueto A.R.: Selenium improves the transport dynamics and energy conservation of the photosynthetic apparatus of in vitro grown Billbergia zebrina (Bromeliaceae). - Photosynthetica 57: 931-941, 2019.

Strasser R.J., Tsimilli-Michael M., Qiang S., Goltsev V.: Simultaneous in vivo recording of prompt and delayed fluorescence and 820-nm reflection changes during drying and after rehydration of the resurrection plant Haberlea rhodopensis. - BBA-Bioenergetics 1797: 1313-1326, 2010.

Strasser R.J., Tsimilli-Michael M., Srivastava A.: Analysis of the chlorophyll $a$ fluorescence transient. - In: Papageorgiou G.C., Govindjee (ed.): Chlorophyll $a$ Fluorescence: A Signature of Photosynthesis. Advances in Photosynthesis and Respiration. Pp. 321-362. Springer, Dordrecht 2004.

Sun Y.P., Liu J., Cao R.X. et al.: Effects of 5-aminolevulinic acid treatment on photosynthesis of strawberry. - Photosynthetica 55: 276-284, 2017.

Takahashi S., Murata N.: How do environmental stresses accelerate photoinhibition? - Trends Plant Sci. 13: 178-182, 2008.

Velikova V., Yordanov I., Edreva A.: Oxidative stress and some antioxidant systems in acid rain-treated bean plants: protective role of exogenous polyamines. - Plant Sci. 151: 59-66, 2000.

Wang N., Tian Y.W., Chen H.: Seed dormancy and germination response of Aegilops tauschii to exogenous application of $\mathrm{GA}_{3}$ and warm water. - Int. J. Agric. Biol. 24: 885-890, 2020.

Wang Y., Zheng W., Zheng W.J. et al.: Physiological and transcriptomic analyses of a yellow-green mutant with high photosynthetic efficiency in wheat (Triticum aestivum L.). Funct. Integr. Genomic. 8: 175-194, 2018.

Wu M.J., Yan Y.R., Wang Y.Q. et al.: Arbuscular mycorrhizal fungi for vegetable (VT) enhance resistance to Rhizoctonia solani in watermelon by alleviating oxidative stress. - Biol. Control 152: 104433, 2021.

Xiao H.G., Yang H.W., Rao Y. et al.: [Analysis of chloroplast ultrastructure, stomatal characteristic parameters and photosynthetic characteristics of chlorophyll-reduced mutant in Brassica napus L.] - Sci. Agr. Sin. 46: 715-727, 2013. [In Chinese]

Yang C., Zhang Y.Y., Fang Z.Y. et al.: [Photosynthetic 
physiological characteristics and chloroplast ultrastructure of yellow leaf mutant $Y L-1$ in cabbage.] - Acta Hortic. Sin. 41: 1133-1144, 2014. [In Chinese]

Yang J., Kong Q., Xiang C.: Effects of low night temperature on pigments, Chl $a$ fluorescence and energy allocation in two bitter gourd (Momordica charantia L.) genotypes. - Acta Physiol. Plant. 31: 285-293, 2009.

Zhang D., Zhang Q.S., Yang X.Q.: Adaptive strategies of Zostera japonica photosynthetic electron transport in response to thermal stress. - Mar. Biol. 164: 35, 2017.
Zhang H., Chen Y., Niu Y. et al.: Characterization and fine mapping of a leaf yellowing mutant in common wheat. - Plant Growth Regul. 92: 233-247, 2020.

Zhang L.M., Lv W.Y., Zhang L.X.: [Agronomic traits and physiological-biochemical characteristics of light-green leaf mutant sll1 of Sorghum bicolor.] - Plant Physiol. J. 50: 14011405, 2014. [In Chinese]

Zhang Z.S., Jia Y.J., Gao H.Y. et al.: Characterization of PSI recovery after chilling-induced photoinhibition in cucumber (Cucumis sativus L.). - Planta 234: 883-889, 2011.

Appendix. Abbreviations of the parameters of the data derived from the transient fluorescence of chlorophyll $a$.

\begin{tabular}{|c|c|}
\hline Fluorescence parameters & Description \\
\hline $\mathrm{M}_{0}=4\left[\left(\mathrm{~F}_{300 \text { us }}-\mathrm{F}_{0}\right) /\left(\mathrm{F}_{\mathrm{M}}-\mathrm{F}_{0}\right)\right]$ & $\begin{array}{l}\text { The initial slope of the relative variable fluorescence of the relative rate at which } \mathrm{Q}_{A} \\
\text { is reduced }\end{array}$ \\
\hline $\mathrm{W}_{\mathrm{K}}=\left(\mathrm{F}_{\mathrm{K}}-\mathrm{F}_{0}\right) /\left(\mathrm{F}_{\mathrm{J}}-\mathrm{F}_{0}\right)$ & The normalized relative variable fluorescence \\
\hline $\mathrm{V}_{\mathrm{J}}=\left(\mathrm{F}_{\mathrm{J}}-\mathrm{F}_{0}\right) /\left(\mathrm{F}_{\mathrm{M}}-\mathrm{F}_{0}\right)$ & Relative variable fluorescence intensity at the J-step \\
\hline $\mathrm{V}_{\mathrm{I}}=\left(\mathrm{F}_{\mathrm{I}}-\mathrm{F}_{0}\right) /\left(\mathrm{F}_{\mathrm{M}}-\mathrm{F}_{0}\right)$ & Relative variable fluorescence intensity at the I-step \\
\hline$\Psi_{0}=\mathrm{ET}_{0} / \mathrm{TR}_{0}=\left(1-\mathrm{V}_{\mathrm{J}}\right)$ & $\begin{array}{l}\text { Probability that a trapped exciton moves an electron into the electron transport chain } \\
\text { beyond } \mathrm{Q}_{\mathrm{A}}^{-}(\text {at } \mathrm{t}=0)\end{array}$ \\
\hline$\varphi \mathrm{E}_{0}=\mathrm{ET}_{0} / \mathrm{ABS}=\left[1-\left(\mathrm{F}_{0} / \mathrm{F}_{\mathrm{m}}\right)\right] \Psi_{0}$ & Quantum yield for electron transport (at $t=0$ ) \\
\hline $\mathrm{S}_{\mathrm{m}}=$ Area $/ \mathrm{F}_{\mathrm{v}}$ & Normalized total complementary area above the OJIP transient \\
\hline $\mathrm{ABS} / \mathrm{RC}=\mathrm{M}_{0}\left(1 / \mathrm{V}_{\mathrm{J}}\right)\left(1 / \varphi \mathrm{P}_{0}\right)$ & Absorption flux per reaction center (RC) \\
\hline $\mathrm{TR}_{0} / \mathrm{RC}=\mathrm{M}_{0}\left(1 / \mathrm{V}_{\mathrm{J}}\right)$ & Trapped energy flux per $\mathrm{RC}($ at $\mathrm{t}=0$ ) \\
\hline $\mathrm{ET}_{0} / \mathrm{RC}=\mathrm{M}_{0}\left(1 / \mathrm{V}_{\mathrm{J}}\right) \psi \mathrm{E}_{0}$ & Electron transport flux per $\mathrm{RC}($ at $\mathrm{t}=0)$ \\
\hline $\mathrm{DI}_{0} / \mathrm{RC}=(\mathrm{ABS} / \mathrm{RC})-\left(\mathrm{TR}_{0} / \mathrm{RC}\right)$ & Dissipated energy flux per RC (at $t=0)$ \\
\hline $\mathrm{RC} / \mathrm{CS}_{0}=\varphi \mathrm{P}_{0}\left(\mathrm{~V}_{\mathrm{J}} / \mathrm{M}_{0}\right)(\mathrm{ABS} / \mathrm{CS})$ & Density of RCs per excited cross section $(\mathrm{CS})($ at $t=0)$ \\
\hline $\mathrm{ABS} / \mathrm{CS}_{0} \approx \mathrm{F}_{\mathrm{m}}$ & Absorption flux per CS (at $t=0)$ \\
\hline $\mathrm{TR}_{0} / \mathrm{CS}_{0}=\varphi \mathrm{P}_{0}(\mathrm{ABS} / \mathrm{CS})$ & Trapped energy flux per CS (at $t=0)$ \\
\hline $\mathrm{ET}_{0} / \mathrm{CS}_{0}=\varphi \mathrm{E}_{0}(\mathrm{ABS} / \mathrm{CS})$ & Electron transport flux per CS (at $t=0)$ \\
\hline $\mathrm{DI}_{0} / \mathrm{CS}_{0}=(\mathrm{ABS} / \mathrm{CS})\left(\mathrm{TR}_{0} / \mathrm{CS}\right)$ & Dissipated energy flux per CS (at $t=0)$ \\
\hline $\mathrm{PI}_{\mathrm{ABS}}=(\mathrm{RC} / \mathrm{ABS})\left[\varphi \mathrm{P}_{0} /\left(1-\varphi \mathrm{P}_{0}\right)\right]\left[\Psi_{0} /\left(1-\Psi_{0}\right)\right]$ & Performance index on absorption basis \\
\hline
\end{tabular}

(C) The authors. This is an open access article distributed under the terms of the Creative Commons BY-NC-ND Licence. 